\title{
The reactive element effect: ionic processes of grain- boundary segregation and diffusion in chromium oxide scales
}

\author{
E A Polman, T Fransen $†$ and P J Gellings \\ University of Twente, Department of Chemical Technology, PO Box 217, \\ 7500 AE Enschede, The Netherlands
}

Received 13 February 1989

\begin{abstract}
The transport processes in chromium oxide reviewed here, are related to the basic ionic processes in oxides. Solid state science has been effective in describing the complicated diffusion-controlled oxide growth of chromium and chromia-forming alloys. Additions of reactive elements to chromia-forming alloys have a remarkably beneficial effect and this effect is also related to ionic transport processes in crystal lattices. Chromia-forming alloys are widely used in coal handling and conversion systems due to their good high-temperature corrosion properties; for industrial applications the requirement is that a good adherent protective oxide with a low diffusion of defects is formed. Recently, improved knowledge has been gained of the identity of the moving species and the values of the corresponding diffusion coefficients in chromia scales. STEM measurements give experimental support for the theory of grain-boundary segregation and blocking of grain-boundary diffusion by reactive elements.

In this paper the current ideas on the transport processes in chromia and the role of rare earth additions on the corrosion behaviour are reviewed. In addition calculations on crystal lattices and grain boundaries are discussed. The calculations on chromia have been beneficially influenced by earlier theoretical considerations on nickel oxide. Consequently, results on (doped) nickel oxide as well as chromium oxide are discussed.
\end{abstract}

\section{Introduction}

For the development of high temperature materials, knowledge and modelling of diffusion processes in corrosion products is very important. Chromia-forming alloys are widely used in process industries and coal-related technologies. The good corrosion resistance of these steels is due to a chromium-rich oxide layer which is formed either in the corrosive atmosphere or during a pre-oxidation treatment. Although scale failures such as cracking or detachment may occur, in general chromia scales offer good protection in various aggressive gas environments.

Addition of 'doping' elements such as cerium, yttrium, lanthanum etc. often leads to improved corrosion resistance. This addition can be made either by means of alloying of the bulk or by enrichment of the surface layer. Examples of methods to obtain surface enrichment are pack cementation, ion implantation, sol-gel dipping or hot dipping. Furthermore, these techniques can be combined with laser glazing.

$\uparrow$ Author to whom all correspondence should be addressed. 


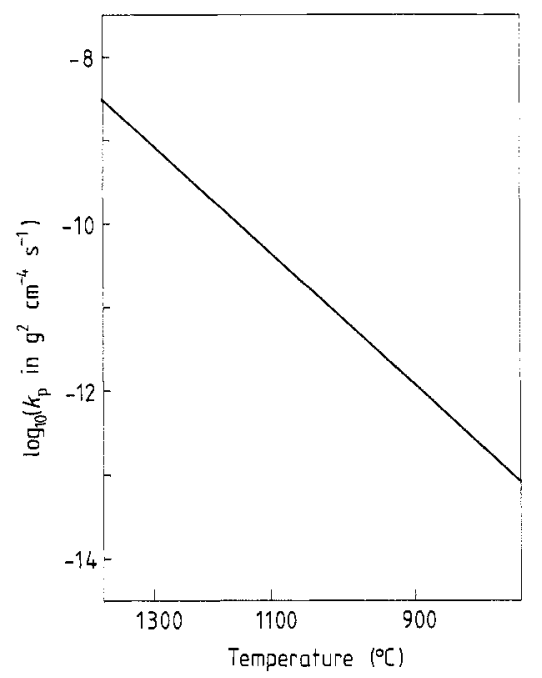

Figure 1. Parabolic rate constants of chromium oxidation. Data from reference [3].

To date, the optimisation of the addition of active elements has been a matter of trial and error. Very little is known about the influences of the amount of these elements, their ionic radii and their solubility in the oxide lattice on the corrosion resistance of the enriched oxide. A good knowledge of the diffusion processes occurring in the oxide may lead to a more fundamental approach to the application of coatings.

In this review, the oxidation kinetics, diffusion parameters and proposed defect transport mechanisms for chromia scales are reviewed. One of the main conclusions is that the oxidation kinetics cannot be explained by bulk diffusion as the main mode of transport, but probably occurs by grain-boundary diffusion in certain temperature regions. The influence of additions of active elements on chromia scales and some of the proposed mechanisms are discussed. It is shown that some defect calculation models agree with the observed corrosion behaviour $[1,2]$. If modelling of the defect migration along grain boundaries in chromium oxide and the influence of rare earth additions on these transport processes support the experimental results, then a worthwhile addition to the current ideas on reactive elements will have been achieved.

\section{The oxidation of pure chromium}

The oxidation of many metals, including chromium, may often by described by means of the parabolic rate law

$$
\mathrm{d}(\Delta x) / \mathrm{d} t=k_{\mathrm{p}} / \Delta x
$$

where $x$ and $k_{\mathrm{p}}$ are the scale thickness and the parabolic rate constant, respectively.

In such cases $k_{\mathrm{p}}$ is determined by diffusion, and it is this mechanism that we address in this section. Diffusion mechanisms and the corresponding activation energies and rates have been successfully modelled in recent years, though not yet for all the systems under discussion. Section 7 describes some such calculations.

Large differences are observed in the parabolic rate constants that have been published in literature. The average values of a set of parabolic rate constants, collected in [3] for oxidation in oxygen in the pressure range $0.1-1$ bar, are given in figure 1 . At 
temperatures higher than $1000^{\circ} \mathrm{C}$ and at high oxygen partial pressures, corrections must be applied for the evaporation of $\mathrm{CrO}_{3}$.

Evidence for the identity of the diffusing species during the growth process was presented by several authors. ${ }^{18} \mathrm{O}$ experiments at $950{ }^{\circ} \mathrm{C} \mathrm{[4]} \mathrm{and} \mathrm{at} 900{ }^{\circ} \mathrm{C}[5]$ revealed that 90 to $100 \%$ of the mass transport can be attributed to outward chromium diffusion in the oxide scale. For long term experiments, the interpretation of ${ }^{18} \mathrm{O}$ as well as of thermogravimetric experiments may be complicated by the large compressive stresses which finally give rise to a scale breakdown. A duplex oxide layer is then formed as a result of gaseous diffusion through the cracks.

The oxidation measurements [6] for chromium at $1000^{\circ} \mathrm{C}$, performed at oxygen partial pressures between $10^{-10}$ and $10^{-14}$ bar, showed that practically no dependence exists between the oxidation rate of chromium and the applied oxygen partial pressure. Recent oxidation measurements on chromium at $900^{\circ} \mathrm{C}$ and $10^{-20}<P_{\mathrm{O}_{2}}<1$ bar, also show $k_{\mathrm{p}}$ to be independent of the oxygen partial pressure [7].

If the lack of dependence of $k_{\mathrm{p}}$ on the oxygen partial pressure is interpreted in terms of bulk diffusion of chromium defects, transport must take place by chromium interstitials. If chromium interstitials with an effective charge $\alpha$ are the majority defects in a chromia scale, then according to Wagner's parabolic equation [8], $k_{\mathrm{p}}$ can be formulated as

$$
k_{\mathrm{p}}=(\alpha+1) D_{\mathrm{Cr}^{0}}\left[\left(P_{\mathrm{O}_{2}}^{\mathrm{i}}\right)^{-3 / 4(\alpha+1)}-\left(P_{\mathrm{O}_{2}}^{\mathrm{g}}\right)^{-3 / 4(\alpha+1)}\right]
$$

where $D_{\mathrm{Cr}^{0}}$ is the self-diffusion coefficient of chromium in chromia in equilibrium with oxygen at unit activity and $P_{\mathrm{O}_{2}}^{\mathrm{i}}$ and $P_{\mathrm{O}_{2}}^{\mathrm{g}}$ are the effective oxygen partial pressures at the inner (metal side) and outer (gas side) scale interfaces, respectively.

Since $P_{\mathrm{O}_{2}}^{\mathrm{i}}$ is the dissociation pressure of chromia in contact with chromium, equation (2) can be rewritten as:

$$
k_{\mathrm{p}} \simeq(\alpha+1) D_{\mathrm{Cr}^{0}}\left(P_{\mathrm{O}_{2}}^{\mathrm{i}}\right)^{-3 / 4(\alpha+1)}=(\alpha+1) D_{\mathrm{Cr}}^{\mathrm{i}}
$$

if $P_{\mathrm{O}_{2}}^{\mathrm{g}}>100 P_{\mathrm{O}_{2}}^{\mathrm{i}}$, which is practically always the case. In equation (3) $D_{\mathrm{Cr}}^{\mathrm{i}}$ is the selfdiffusion coefficient of chromium in chromia near the inner scale interface.

This means that a chromium interstitial defect mechanism leads to oxidation behaviour which is independent of the oxygen partial pressure.

If chromium vacancies dominate the growth process in the bulk of the oxide, then $k_{\mathrm{p}}$ can be formulated as

$$
k_{\mathrm{p}}=(\alpha+1) D_{\mathrm{Cr}^{0}}\left[\left(P_{\mathrm{O}_{2}}^{\mathrm{g}}\right)^{3 / \dot{4}(\alpha+1)}-\left(P_{\mathrm{O}_{2}}^{\mathrm{i}}\right)^{3 / 4(\alpha+1)}\right]
$$

and consequently diffusion by chromium vacancies gives rise to an easily measurable dependence of $k_{\mathrm{p}}$ on the oxygen partial pressure, because $P_{\mathrm{O}_{2}}^{\mathrm{i}} \ll P_{\mathrm{O}_{2}}^{\mathrm{g}}$.

It should be taken into consideration that these defect mechanisms hold for bulk diffusion. However, grain-boundary diffusion is generally considered to be the main transport mechanism. Although it is not certain whether the defect mechanisms are the same at a grain boundary as in the bulk phase, it is probable that these conclusions remain unchanged.

\section{The oxidation of chromium alloys}

Metals such as iron, nickel and cobalt are often alloyed with chromium to obtain chromiaforming materials with good mechanical properties and high oxidation resistance. The 


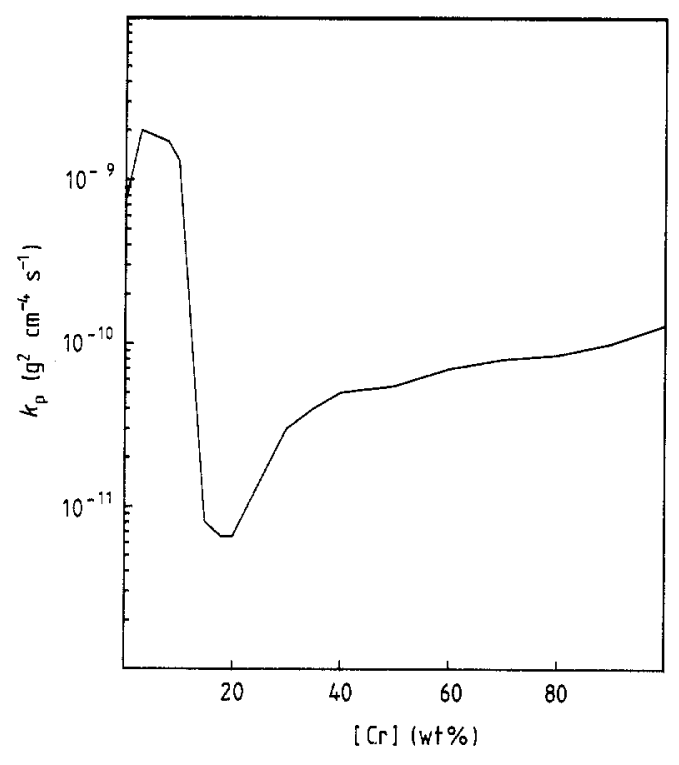

Figure 2. Variation of the parabolic rate constant $k_{\mathrm{p}}$ with alloy composition for $\mathrm{Ni}-\mathrm{Cr}$ alloys at $1000^{\circ} \mathrm{C}$ in oxygen at $1 \mathrm{~atm}$. From reference [9].

alloy inter-diffusion coefficients and the diffusivity of chromium in $\mathrm{Cr}_{2} \mathrm{O}_{3}$ are such that selective oxidation almost inevitably leads to chromium depletion in the alloy near the interface. Due to this chromium depletion other oxides and spinel phases are formed and the thickness of the chromia is limited. The result is that continuous scale breakdown does not take place. Especially in nickel-chromium alloys this breakdown is reduced even further due to the internal oxidation of the alloy grain boundaries, giving rise to better scale adhesion.

The parabolic oxidation rate constant of a chromium-containing alloy is as a rule smaller than the corresponding value for pure chromium. The variation of $k_{\mathrm{p}}$ with the composition of nickel-chromium alloys at $1000^{\circ} \mathrm{C}$ in $\mathrm{O}_{2}$ is shown in figure 2 .

One explanation for the decrease of $k_{\mathrm{p}}$ upon doping with nickel is that this is electrically compensated in the lattice by a decrease in the concentration of chromium vacancies. If the main transport takes place by a chromium vacancy mechanism, doping with nickel should indeed lead to a decrease in $k_{\mathrm{p}}$ [10]. Another explanation for the doping effect of ions with a lower valence was given in [6]. Assuming that chromium interstitials are the main defects in the oxide, a decrease in the chromium activity at the alloy-oxide interface leads to decrease in the oxidation rate.

\section{Tracer diffusion experiments}

Tracer diffusion experiments with ${ }^{51} \mathrm{Cr}$ and ${ }^{18} \mathrm{O}$ can give information about the diffusion coefficients of the species in the oxide scale. The results of experiments [11-13] on sintered or hot-pressed samples were roughly in agreement with the bulk defect models considered. It was found in [12] that oxygen diffusion was much slower than chromium diffusion. It was generally assumed that bulk diffusion is the main transport process and it has been shown that the magnitude of the measured diffusion values of chromium are 


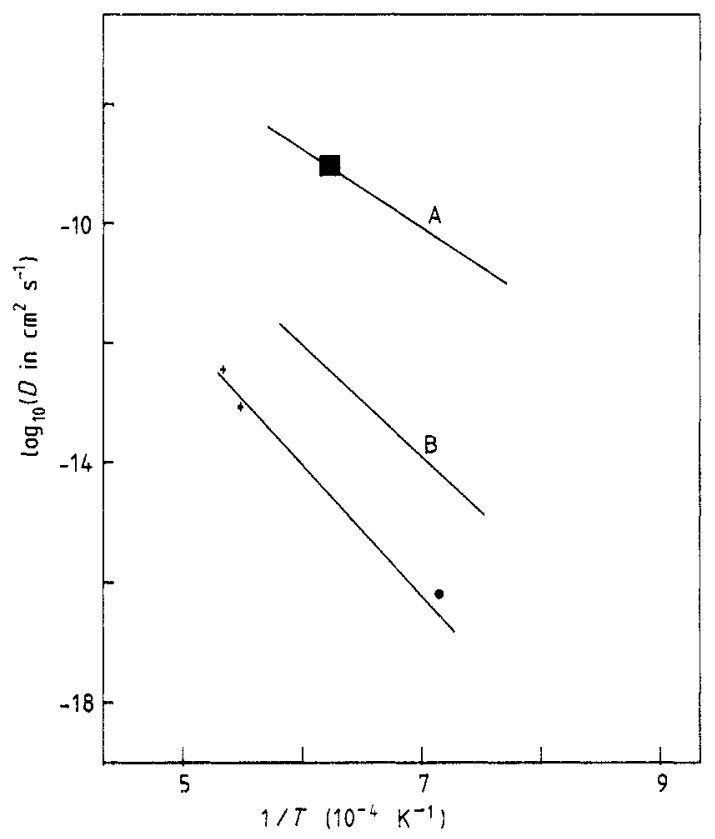

Figure 3. Diffusion coefficients as determined by tracer experiments of chromium and oxygen in $\mathrm{Cr}_{2} \mathrm{O}_{3}$. $\mathrm{m}$, $\mathrm{Cr}$ diffusion in single crystals [11]; $\mathrm{A}, \mathrm{Cr}$ diffusion in hot chromia [12]; B, O-diffusion by gas-solid isotope exchange [15]; + , Cr diffusion [16] in single crystals; $\mathrm{Cr}$ diffusion [17] in single crystals.

in agreement with the observed $k_{\mathrm{p}}$-value [14]. A survey of the various diffusion data is given in figure 3 .

The chromium tracer self-diffusion experiments on chromia single crystals [17] gave rise to a completely different view of the oxidation process of chromium. The obtained penetration profiles of ${ }^{51} \mathrm{Cr}$ could be divided into a steep slope near the surface, characteristic of bulk diffusion, and a 'tail' characteristic of diffusion along dislocations. It was assumed that the dislocations are arranged in arrays forming low-angle grain boundaries. The profiles are analysed by comparing the observed profile with a mathematically fitted curve [18]. By fitting the observed profile, the lattice diffusion coefficient $D$ and the product $D^{\prime} \delta$ can be obtained. $D^{\prime}$ stands for the grain-boundary diffusion coefficient and $\delta$ for the grain boundary width.

From figure 3 it is clear that the data obtained in [17] for bulk diffusion are about 5 orders of magnitude smaller than those previously obtained. The only possible explanation is that the former data are characteristic of short-circuit diffusion. It is remarkable that the measurements in [11] on single crystals do not agree with the data from [17], as is seen in the same figure. The possible presence of a mosaic structure could be an explanation for the data obtained in [11].

In figure 4 the variation of the chromium lattice diffusion coefficient $D$ and of the product $D^{\prime} \delta$ with the oxygen partial pressure is illustrated [18].

Although the measured values are characterised by a large experimental error, they seem in accordance with a chromium-vacancy mechanism because a decrease in $P_{\mathrm{O}_{2}}$ generally leads to a decrease in the diffusion coefficients. According to [18], the increase of the diffusion coefficients at $P_{\mathrm{O}_{2}}$ near the equilibrium partial pressure of $\mathrm{Cr}_{2} \mathrm{O}_{3}$ can be explained by a change in the defect structure caused by the formation of chromium interstitials at these low oxygen pressures.

The most important conclusion from $[17,18]$ is that the growth process of chromia at moderate temperatures cannot be described by lattice diffusion because lattice diffusion is too slow to account for the measured $k_{\mathrm{p}}$-values. 


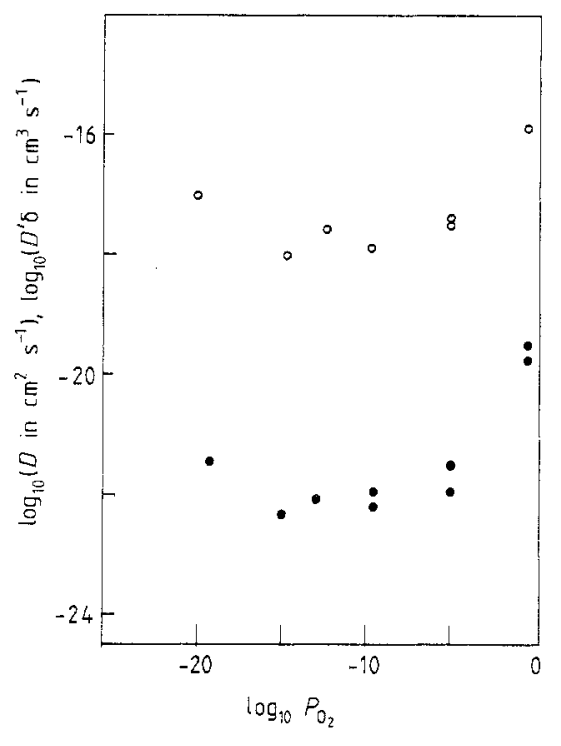

Figure 4. ${ }^{51} \mathrm{Cr}$ diffusion: $\mathrm{O}, D$ in the $\mathrm{Cr}_{2} \mathrm{O}_{3}$ lattice; - $D^{\prime} \delta$ along low-angle grain boundaries, as a function of oxygen partial pressure $P_{\mathrm{O}_{2}}$ at $1100^{\circ} \mathrm{C}$. Data obtained in [18].

\section{The electrical conductivity of chromium oxide}

The electrical conductivity of sintered chromium oxide powders was reviewed in [19]. The defect chemistry of chromium oxide was divided into two parts: a low temperature region $\left(T<1250^{\circ} \mathrm{C}\right)$ and a high temperature region, where the conduction takes place by intrinsic defects (intrinsic or self-defect conductivity). In the low temperature region the conductivity can be determined by the amount of impurities in the oxide. Doping with ions with a valency lower than 3 leads, as a consequence of the electroneutrality condition, to a decrease in the concentration of metal vacancies and an increase in the number of electron holes. Therefore the chromia measured at low temperatures and contaminated with lower valence ions is always p-type. Doping with electron donors such as $\mathrm{W}, \mathrm{Ti}, \mathrm{Nb}$ or $\mathrm{V}$ may result in n-type behaviour depending on the solubility of the dopant.

Recent measurements on sintered chromium oxide tablets resulted in a new view on the defect mechanism of $\mathrm{Cr}_{2} \mathrm{O}_{3}$ [20]. The thermoelectric power measurements on $\mathrm{Cr}_{2} \mathrm{O}_{3}$, sintered in different atmospheres and at various temperatures, showed that n-type behaviour occurs when the chromia is sintered at low oxygen partial pressures and ptype on sintering at high $P_{\mathrm{O}_{2}}$. The defect structure is 'frozen' below the temperature at which sintering was carried out. For specimens sintered at $1770 \mathrm{~K}$ in a $\mathrm{H}_{2} / \mathrm{H}_{2} \mathrm{O}$ gas mixture, the transition in air from $\mathrm{n}$ - to p-type is a relatively fast process at $1300 \mathrm{~K}$. The reverse transition from $\mathrm{p}$ - to n-type only takes place at temperatures above $1800 \mathrm{~K}$ at low oxygen partial pressures. The fact that the value for the thermopower never equilibrates to zero in the experiments shows no evidence for intrinsic conductivity up to $1800 \mathrm{~K}$. The experiments [20] showed that if the value for the band gap, derived from experiments of [21] to be $3.6 \mathrm{eV}$, is used to calculate the intrinsic electron-hole concentration, the contribution of intrinsic conductivity may be neglected.

The dependence of the n- or p-type behaviour on the oxygen partial pressure is in agreement with the presence of chromium interstitial defects at low oxygen partial pressures and chromium vacancies at high oxygen partial pressures. In [20], it was 
considered unlikely that equilibration with the local oxygen partial pressure was obtained at moderate temperatures $(900-1100 \mathrm{~K})$ in a chromia scale, formed after oxidation of chromium.

\section{The 'rare earth effect' in chromium and chromia-forming alloys}

The addition of rare earths to chromia-forming alloys has a large beneficial effect on the corrosion behaviour of alloys. Because the beneficial effect is not limited to rare earths, as indicated in [22], it is better to speak of reactive elements. Dopants may influence the oxidation rate by changing the concentration of charge carriers if they have a higher or lower valency. This effect of dopant valency is not the only significant effect. This raises important issues not yet fully analysed in terms of solid state mechanisms. We shall show that the combination of experiment and theory does yield a consistent picture of the reactive element effect. Much research was done on the alloying of metals with dispersed oxide phases. Dispersed oxide phases such as $\mathrm{ThO}_{2}, \mathrm{CeO}_{2}$ or $\mathrm{Y}_{2} \mathrm{O}_{3}$ were added to Ni$\mathrm{Cr}, \mathrm{Co}-\mathrm{Cr}$ and $\mathrm{Fe}-\mathrm{Cr}$ base alloys [23-25]. The beneficial effect was evident and the following observations were made:

(i) the amount of chromium, necessary to form a continuous $\mathrm{Cr}_{2} \mathrm{O}_{3}$ layer, can be reduced;

(ii) the overall oxidation rate is decreased;

(iii) the oxide scale is more adherent and less oxide spallation occurs.

It was shown that for $\mathrm{Co}-\mathrm{Cr}$ alloys the reactive elements, present in the alloys, should first internally be pre-oxidised [26]. If this pretreatment is not carried out, no beneficial effect is observed.

Instead of alloying, the reactive elements can also be applied on the surface, such as by sol-gel coating, by ion implantation or by pack cementation. The results obtained by ion implantation are discussed below.

It has been shown [5] that yttrium ion-implantation at a dose of $2 \times 10^{16} \mathrm{Y} \mathrm{cm}^{-2}$ in high-purity chromium results in a large reduction of the oxidation rate at $900^{\circ} \mathrm{C}$. By means of ${ }^{18} \mathrm{O}$ experiments it was also shown that the growth mechanism is changed by ion implantation. The unimplanted chromium shows almost $100 \%$ outward growth of the oxide and after ion implantation the amount of outward growth is significantly reduced. This indicates that at least the chromium diffusion within the chromia scale is reduced to a greater extent than the oxygen diffusion. The infiuences of $\mathrm{Y}, \mathrm{Ce}$ and $\mathrm{La}$ implantation on the oxidation of $20 \mathrm{Cr}-25 \mathrm{Ni}-\mathrm{Nb}$-stabilised steel have been extensively investigated [27]. A beneficial effect on the oxidation rate and the amount of oxide spallation was obtained. An implantated dose higher than $10^{16}$ ion $\mathrm{cm}^{-2}$ did not result in a further improvement on oxidation [28]. Ion implantation in $20 \mathrm{Cr}-25 \mathrm{Ni}-\mathrm{Nb}$-stabilised steel did not result in an oxide layer with a higher chromium content [29]. Ion implantation can also be applied to improve the sulphidation corrosion resistance of chromiaforming alloys, if a pre-oxidising treatment is applied, as shown in [30].

The several mechanisms proposed for the reactive element effect on oxidation were summarised in $[31,32]$. The various mechanisms can be divided into three categories, the effects on the initial oxidation $(\$ 6.1)$, the effects on the inhibition of scale failure $(\$ 6.2)$ and the effects on the reduction of the growth rate $(\S 6.3)$. These will now be examined in turn. 


\subsection{Effects on the initial oxidation}

The effects on the initial oxidation behaviour are the heterogeneous nucleation of oxide, the modification of the diffusional properties of alloys and the formation of a barrier layer. The model of heterogeneous nucleation of chromia grains on rare-earth dispersoids may be a valid mechanism for several reactive-element-substrate combinations. In this model it is proposed that due to the reactive-element dispersoids, acting as nucleation sites, the spacing of these sites is decreased giving rise to earlier formation of a closed chromia layer. This model is able to explain the decrease of the minimum chromium concentration in the alloy necessary to form a continuous chromia layer. However, addition of reactive elements does not always lead to a chromia-enriched oxide layer [29] and the model is also not able to explain the effects of yttrium ionimplantation in pure chromium. The modification of the alloy diffusional properties is in contrast with experimental results [33], indicating that the chromium diffusion is reduced instead of enhanced in a $\mathrm{Ni}-20 \mathrm{Cr}$ alloy with $\mathrm{Y}$ additions. The formation of a perfectly closed barrier layer in the early stages of oxidation is also not a likely mechanism since it is not able to explain the beneficial effects of preformed dispersed oxides.

\subsection{Effects on the inhibition of scale failure}

The inhibition of scale failure will not be further discussed in this paper. It is clear that before scale cracking occurs, the oxidation rate is reduced due to the addition of reactive elements. The beneficial effects of reactive elements on scale failure are evident but in this review their influence on the transport properties is highlighted.

\subsection{Effects on the reduction of the growth rate}

The mechanisms effective for the reduction of the growth rate are limited to the effects on the blocking of fast diffusion paths, because at temperatures below $1100{ }^{\circ} \mathrm{C}$ the oxidation is dominated by short-circuit diffusion. The proposed mechanisms involving short-circuit diffusion are given in $\$ \$ 6.3 .1-6.3 .4$.

6.3.1. The physical blocking by segregated reactive elements along grain boundaries and dislocations. Attractive and repulsive forces are not considered in this model [34]. Due to segregation of reactive elements at grain boundaries, occupying chromium sites, the amount of chromium along the grain boundary is reduced. The chromium grainboundary diffusion may then be formulated as

$$
D_{\mathrm{Cr}}=\alpha_{\mathrm{Cr}} D_{\mathrm{Cr}}{ }^{0} \delta
$$

where $\alpha_{\mathrm{Cr}}$ is the segregation factor for chromium given by the concentration of chromium at the grain boundaries divided by the concentration of chromium in bulk $\mathrm{Cr}_{2} \mathrm{O}_{3} . D_{\mathrm{Cr}^{0}}$ is the grain-boundary diffusion coefficient for chromium in pure $\mathrm{Cr}_{2} \mathrm{O}_{3}$ and $\delta$ is the grain boundary width.

6.3.2. The formation of complex defects between defects and reactive element ions. Due to the interaction of defects with reactive element ions at the grain boundaries, the 
activation energy for defect migration along grain boundaries may be increased. This model is supported by the defect model calculations in [1]. They showed that nickel vacancy migration along grain boundaries of $\mathrm{NiO}$ was hindered by interactions of the vacancies with cerium ions substituting a nickel position. This model is discussed in $\S 7$.

6.3.3. Physical blocking by second phase particles on grain boundaries. In this model it is assumed that a coherent interface can be formed between second phase particles (e.g. $\mathrm{YCrO}_{3}$ ) and oxide grains. However, it is unlikely that very small additions of reactive elements can occupy the $\mathrm{Cr}_{2} \mathrm{O}_{3}$ grain boundaries to such a large extent as to account for the drastic decrease in the growth rate.

6.3.4. Alteration in the number and character of short-circuit diffusion paths. It was suggested [23] that due to the reduction of the oxide grain size the number of dislocations could be reduced, since dislocations are unstable in smaller grains. This mechanism is inconsistent with the observation that smaller grains lead to an increase of the oxidation rate [35].

Evidence for the role of grain-boundary segregation of reactive elements in $\mathrm{Cr}_{2} \mathrm{O}_{3}$ was given by the experiments $[36,37]$. STEM measurements revealed that segregation of yttrium at the chromia grain boundaries does indeed occur. For $2 \times 10^{16} \mathrm{Y} \mathrm{cm}-2$ implanted $\mathrm{Co}-45 \mathrm{Cr}$, the measured $\mathrm{Y}: \mathrm{Cr}$ ratio at the grain boundary may correspond to a complete monolayer coverage by yttrium, if all the yttrium is concentrated in the layer immediately adjacent to the grain boundary, as shown in [37]. The exact distribution at the grain boundary cannot be measured because of the relatively large beam diameter.

The measurements in $[36,37]$ provide no proof for the reduction of cation diffusion along grain boundaries but greatly support the mechanisms based on grain-boundary segregation. These mechanisms were proposed many years before grain-boundary segregation could be observed experimentally. The processes occurring at the oxide grain boundary may be due to physical blocking, complex defect formation or the action of yttrium as an iso-electronic donor. It has been suggested [38] that yttrium may act as an iso-electronic donor in $\mathrm{Al}_{2} \mathrm{O}_{3}$. It has also been proposed [39] that yttrium can act as an iso-electronic donor in $\mathrm{Cr}_{2} \mathrm{O}_{3}$, leading to a decrease in the concentration of chromium interstitials.

\section{Defect calculations in the lattice}

Extensive studies based on calculations of simulated crystal lattices have been carried out in the last 15 years. The defect calculations discussed here are all derived from the method introduced by Mott and Littleton [40]. This method was further developed [41-43] for cubic materials. The model for non-cubic materials was extended [44] to show the necessity of introducing anisotropy into the model for a proper calculation of the defect formation in $\mathrm{TiO}_{2}$ and $\mathrm{Al}_{2} \mathrm{O}_{3}$. The modified model is calculated with the PROGRAM HADES 3 (Harwell Automatic Defect Examination System) [42, 43].

Calculations have recently been performed on the formation of defects in the lattice of $\mathrm{Cr}_{2} \mathrm{O}_{3}[2,45]$. Due to the different potential models they used, the obtained values for the defect formation and defect migration energies are slightly different. The qualitative 


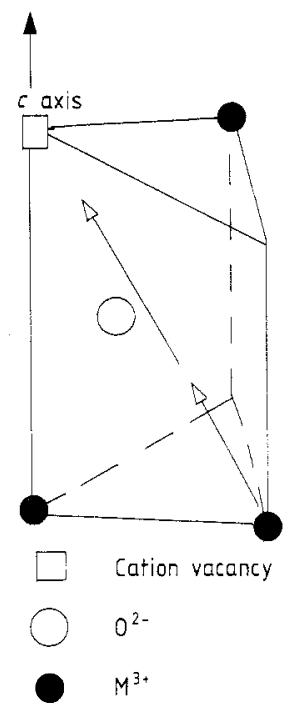

Figure 5. The $\mathrm{C} 4$ mechanism for chromium vacancy migration in a $\mathrm{Cr}_{2} \mathrm{O}_{3}$ lattice (see $\$ 7$ of text).

conclusions in [2] and [45] are however the same. The calculated value of the band gap, found in [2], of $203 \mathrm{~kJ} \mathrm{~mol}^{-1}$ between a large polaron hole and a small polaron electron, which both turned out to be the most stable species, seems too low considering the estimated value of $346 \mathrm{~kJ} \mathrm{~mol}^{-1}$ [21] and the experiments [20] mentioned previously. In [2] it was supposed that a contribution to the electron formation energy of $+\frac{3}{5} \Delta$, in which $\Delta$ is the ligand field splitting energy, has to be added. This leads to a value of $377 \mathrm{~kJ}$ $\mathrm{mol}^{-1}$, which is in better agreement with the experimental values. The lower limit of the band gap was calculated [45] to be $352 \mathrm{~kJ} \mathrm{~mol}^{-1}$ when all crystal field terms are neglected.

The energetically most favourable bulk diffusion mechanisms for vacancy motion, anion migration and interstitial migration in $\mathrm{Cr}_{2} \mathrm{O}_{3}$ were also calculated in [2] and [46]. Out of the six possible mechanisms for cation vacancy motion, proposed by James for $\mathrm{Al}_{2} \mathrm{O}_{3}$ [47], only the relevant mechanisms will be mentioned. The $\mathrm{C} 3$ mechanism in which a cation moves along the $c$ axis from an octahedral interstitial site towards a cation vacancy, turned out to be the most favourable. However, the diffusion parallel to the $c$ axis will be blocked by the highly unfavourable $\mathrm{C} 1$ mechanism. Bulk diffusion in chromia probably takes place by the $\mathrm{C} 4$ mechanism (see figure 5), where migration parallel and perpendicular to the $c$ axis occurs.

For anion vacancy motion, the so-called $\mathrm{A} 1$ mechanism, in which a migrating anion moves between two oxygen sites in the anion triangle shared between two $\mathrm{MO}_{6}$ octahedra, is the energetically preferred mechanism (see figure 6). The A1 mechanism will only affect diffusion in the $a b$ plane.

Cation interstitial migration was calculated for $\mathrm{Fe}_{2} \mathrm{O}_{3}$ [44], the results are probably similar to $\mathrm{Cr}_{2} \mathrm{O}_{3}$ for which the $\mathrm{I} 3$ mechanism, shown in figure 7, turned out to be preferable. In the $\mathrm{I} 3$ mechanism an interstitial ion moves along the $c$ axis towards a lattice cation which is in turn again displaced to the nearest interstitial site in the $a b$ plane.

The calculated values for the activation energy of cation vacancy migration in $\mathrm{Cr}_{2} \mathrm{O}_{3}$ are in agreement with the experimentally determined Arrhenius energies measured for $\mathrm{Cr}$ diffusion [48-50]. For oxidation at low oxygen partial pressures, the formation 


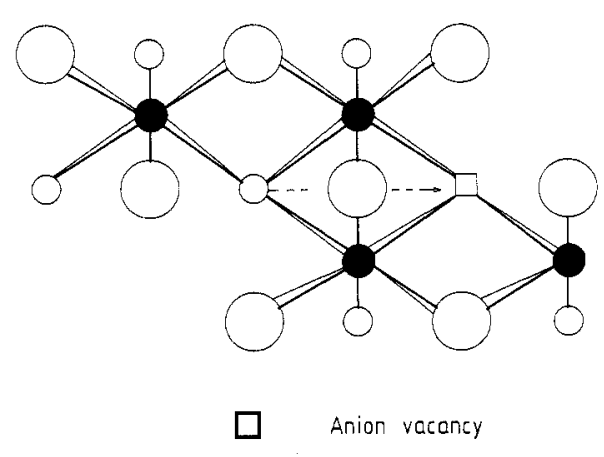

Figure 6. The A1 mechanism for anion vacancy migration in a $\mathrm{Cr}_{2} \mathrm{O}_{3}$ lattice (see $\$ 7$ of text).

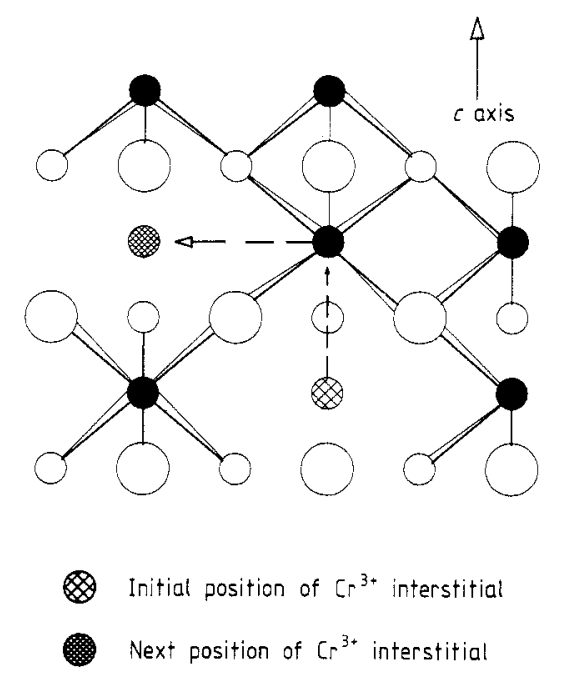

Figure 7. The $\mathrm{I} 3$ mechanism for chromium interstitial migration in a $\mathrm{Cr}_{2} \mathrm{O}_{3}$ lattice (see $\$ 7$ of text).

energies for anion vacancies and cation interstitials are quite similar. A mass-action formalism has been applied to the obtained energies for the defect reactions [45]. They found that chromium interstitials predominate at low $P_{\mathrm{O}_{2}}$ and chromium vacancies at high $P_{\mathrm{O}_{2}}$, in accordance with [14] and [20].

\section{Grain boundary calculations}

Calculations on grain boundaries in $\mathrm{NiO}$, having the rock salt structure, were carried out in $[1,51-55]$.

For $\mathrm{NiO}$ it turned out that compared with the bulk, vacancy formation is favoured for all calculated tilt boundaries. For the boundary plane (211)/[011] the diffusion coefficient at this boundary at $1000 \mathrm{~K}$ is 40 times greater than for bulk vacancy diffusion [51]. The difference between the energies of formation of positively and negatively charged defects leads to a boundary charge. It is assumed that this charge is compensated by a space charge layer.

Calculations on vacancy hopping were modelled by removing two cations from the relaxed grain-boundary structure and introducing an interstitial cation between the two vacancies. One of the coordinates of the interstitial is fixed and the structure is relaxed to equilibrium. This procedure is repeated for several starting positions. The difference between the highest and lowest energy of the diffusion path is the activation energy for vacancy hopping. The observed activation energy for vacancy diffusion at various grain boundaries is $0.56-0.77$ times the activation energy for bulk diffusion. This ratio is in agreement with the observed ratio of 0.7 for polycrystalline nickel oxide [1].

The modelling of cation vacancy migration along an isolated $\mathrm{Ce}_{\mathrm{Ni}}$ ion at a (310)/[001] tilt boundary, showed that the activation energy is increased compared with that for vacancy migration along an undoped grain boundary. This effect is in agreement with the experimental observation that the oxidation rate of $\mathrm{Ni}$ is decreased if a homogeneous thin layer of $\mathrm{Ce}$ particles is deposited [56]. It is assumed here that a dense array 
of $\mathrm{Ce} \ddot{\mathrm{Ni}}_{\mathrm{i}}-\mathrm{v}_{\mathrm{Ni}}$ pairs gives a further increase of the activation energy of migration, although it was not possible to locate the diffusion path [1].

It was also shown that in $\mathrm{NiO}$ the segregation of impurities at grain boundaries is enhanced if the ionic radius of the impurity increases [52]. According to these calculations, very large amounts of impurities might accumulate at the grain boundaries. However, the calculated energies of 'solution' very near the grain boundaries are still very high. This means that either the impurities segregate as second-phase particles or the energy of solution at grain boundaries is not calculated correctly. The dependence of segregation on the size misfit of the impurity ion in the host lattice was found to be linear.

Grain boundary calculations on corundum-type crystals were performed in [57] for $\mathrm{Al}_{2} \mathrm{O}_{3}$ and in [46] for $\mathrm{Cr}_{2} \mathrm{O}_{3}$. They both found that segregation of yttrium at the free surfaces of low index planes is an energetically favourable process except for the basal plane with the hexagonal indices [0001]. Calculations were also performed on the [1012] and the $[10 \overline{10}]$ mirror twin boundaries [46]. The heat of segregation of yttrium to the $[10 \overline{1} 2]$ mirror twin is approximately $50 \mathrm{~kJ} \mathrm{~mol}^{-1}$. The $[10 \overline{1} 0]$ mirror twin shows however no tendency for yttrium segregation. The vacancy formation energy at the [1012] mirror twin boundary is favoured by $322 \mathrm{~kJ} \mathrm{~mol}^{-1}$ towards the bulk value. No diffusion path with a low activation energy along the [1012] twin boundary could be found [46]. The diffusion paths parallel to this boundary all have activation energies in excess of $700 \mathrm{~kJ}$ $\mathrm{mol}^{-1}$. Summarising, it may be stated that the programs used in these calculations of surfaces and grain boundaries are very powerful and make it possible to calculate:

(i) defect energy formation along grain boundaries;

(ii) activation energy of defect migration, with and without impurities;

(iii) solubility of impurities along grain boundaries;

(iv) segregation of impurities.

\section{Concluding remarks}

The cation transport in chromium oxide most probably takes place along grain boundaries. The measurements on chromia single crystals $[17,18]$ show that bulk diffusion is much too slow to account for the observed oxidation rates of chromium.

The measurements on sintered chromia tablets [20] as well as the diffusion experiments $[17,18]$ give evidence for a vacancy defect-mechanism at high oxygen partial pressures and a chromium interstitial defect transport at very low oxygen partial pressures. Although the chromium vacancy mechanism is assumed to occur at moderate temperatures, it fails to explain the observed independence of the oxidation rate from the oxygen partial pressure.

Reactive elements reduce the oxidation rate of chromium and chromia-forming alloys. Segregation of reactive elements at grain boundaries is observed by means of STEM measurements and it is possible to explain the reduced oxidation rate by means of grain-boundary segregation. The reactive element effect may occur by means of physical blocking but it is not certain whether the solubility of reactive elements is high enough to explain the reduction of the oxidation rate by this model. The interaction of reactive elements with defects at chromia grain boundaries is another possible mechanism to explain the reactive element effect. Calculations on chromia support the experimental findings that in the bulk, chromium vacancies predominate at high $P_{\mathrm{O}_{2}}$ and chromium 
interstitials at low $P_{\mathrm{O}_{2}}$. Lattice simulations also support the phenomenon of rare-earth segregation to chromia grain boundaries.

\section{References}

[1] Duffy D M and Tasker P W 1986 Phil. Mag. A 54759

[2] Catlow C R A, Corish J, Henessy J and Mackrodt W C 1988 J. Am. Ceram. Soc. 7142

[3] Hindam H and Whittle D P 1982 Oxid. Met. 18245

[4] Skeldon M, Calvert J M and Lees D G 1987 Oxid. Met. 28109

[5] Cotell C M, Yurek G J, Hussey R J, Mitchell D F and Graham M J 1987 J. Electrochem. Soc. 1341871

[6] Hindam H and Whittle D P 1983 J. Electrochem. Soc. 1301519

[7] Polman E A, Fransen T and Gellings P J 1987 Proc. 10th Int. Congress on Metallic Corrosion, Madras vol 4 (New Delhi: Mohan Primlami) p 3631

[8] Kofstad P 1966 High Temperature Oxidation of Metals ed. R T Foley, N Hackerman, C V King, F L LaQue and H H Uhlig (New York: Wiley)

[9] Wallwork G R 1976 Rep. Prog. Phys. 39401

[10] Atkinson H V 1985 Oxid. Met. 24177

[11] Walters L C and Grace R E 1965 J. Appl. Phys. 362331

[12] Hagel W C and Seybolt A U 1961 J. Electrochem. Soc. 1081146

[13] Lindner R and Åkerstrom A 1956 Z. Phys. Chem. NF 6162

[14] Kofstad P and Lillerud K P 1980 J. Electrochem. Soc. 1272410

[15] Hagel W C 1965 J. Am. Ceram. Soc. 4870

[16] Hoshino K and Peterson N L 1983 J. Am. Ceram. Soc. 66 C202

[17] Atkinson A and Taylor R I 1984 Nato ASI Series B, vol 129 (New York: Plenum) p 285

[18] Atkinson A and Taylor R I 1986 J. Phys. Chem. Solids 47315

[19] Kröger F A 1983 Corrosion (Houston), NACE-6 ed. R A Rapp pp 89-100

[20] Young E W A, Gerretsen J H and De Wit J H W 1987 J. Electrochem. Soc. 1342257

[21] Hay K A, Hicks F G and Holmes D R 1970 Werkstoffe und Korrosion 21917

[22] Pfeil L B 1945 UK Patent Specification 574088

[23] Stringer J, Wilcox B A and Jaffee R I 1972 Oxid. Met. 511

[24] Stringer J and Wright I G 1972 Oxid Met. 559

[25] Wright I G and Wilcox B A 1974 Oxid. Met. 8283

[26] Whittle D P, El-Dashan M E and Stringer J 1977 Corrosion Science 17879

[27] Bennett M J, Bishop H E, Chalker P R and Tuson A T 1987 Mater. Sci. Eng. 90177

[28] Bennett M J, Dearnaley G, Houlton M R and Haws R W M 1982 Proc. Int. Conf. on the Modifications of Surface Properties of Metals by Ion Implantation 1981 ed. V Ashworth (Oxford: Pergamon) pp 264-76

[29] Bennett M J, Bellamy B A, Knights C F, Meadows N and Eyre N J 1985 Mater. Sci. Eng. 69359

[30] Polman E A, Fransen T and Gellings P J 1988 Mater. Sci. Eng. 88157

[31] Whittle D P and Stringer J 1980 Phil. Trans, R. Soc. A 295309

[32] Moon D P and Bennett M J 1987 AERE Report No. R-12757

[33] Delaunay D, Huntz A M and Lacombe P 1979 Scr. Metall. 13419

[34] Gibbs G B 1966 Phys. Status Solidi 16 K27

[35] Ecer G M and Meier G H 1979 Oxid. Met. 13159

[36] Yurek G J, Przybylski K and Garratt-Reed 1987 J. Electrochem. Soc. 1342643

[37] rrzybylski K, Garratt-Reed A J and Yurek G J 1988 J. Electrochem. Soc. 135509

[38] El-Aiat M M and Kröger F A 1982 J. Am. Ceram. Soc. 65162

[39] Ramanarayanan T A and Petkovic-Luton R 1985 Ber. Bunsenges. Phys. Chem. 89402

[40] Mott N F and Littleton M J 1938 Trans. Faraday Soc. 34485

[41] Lidiard A B and Norgett M J 1972 Computational Solid State Physics ed. F Herman, N W Dalton and T R Koehler (New York: Plenum) p 385

[42] Norgett M J 1972 AERE Report No. AERE-R7015

[43] Norgett M J 1974 AERE Report No. AERE-R7650

[44] Catlow C R A, James R, Mackrodt W C and Stewart R F 1982 Phys. Rev. B 251006

[45] Lawrence P J, Parker S C and Tasker P W 1987 Adv. Ceram. ed. C R A Catlow and W C Mackrodt (Westerville, OH: American Ceramic Society) vol 23, p 247 
[46] Lawrence P J 1988 PhD Thesis University of Bath

[47] James R 1979 PhD Thesis University of London

[48] Hoshino K and Peterson N L 1985 J. Phys. Chem. Solids 46469

[49] Grescovich C 1984 J. Am. Ceram. Soc. 67 C111

[50] Hoshino K and Peterson N L 1983 J. Am. Ceram. Soc. 66 C202

[51] Duffy D M and Tasker P W 1984 Phil. Mag. A 50143

[52] Duffy D M and Tasker P W 1984 Phil. Mag. A 50155

[53] Duffy D M and Tasker P W 1983 Phil. Mag. A 47817

[54] Tasker P W and Duffy D M 1983 Phil. Mag. A 47 L45

[55] Duffy D M and Tasker P W 1983 Phil. Mag. A 48155

[56] Chadwick A T and Taylor R I 1984 Proc. 9th Int. Congress on Metallic Corrosion ed. National Research Council of Canada (Ottawa: NRC Canada) vol 3, p 381

[57] Mackrodt W C 1987 Advances in Ceramics ed. C R A Catlow and W C Mackrodt (Westerville, $\mathrm{OH}$ : American Ceramic Society) vol 23, p 293 